\title{
A scoping review on the roles and tasks of peer reviewers in the manuscript review process in biomedical journals
}

\author{
Ketevan Glonti ${ }^{1,2,3^{*}}$ D, Daniel Cauchi ${ }^{4}$, Erik Cobo ${ }^{5}$, Isabelle Boutron ${ }^{2,3}$, David Moher ${ }^{6}$ and Darko Hren ${ }^{1}$
}

\begin{abstract}
Background: Although peer reviewers play a key role in the manuscript review process, their roles and tasks are poorly defined. Clarity around this issue is important as it may influence the quality of peer reviewer reports. This scoping review explored the roles and tasks of peer reviewers of biomedical journals.

Methods: Comprehensive literature searches were conducted in Cochrane Library, Cumulative Index to Nursing and Allied Health Literature, Educational Resources Information Center, EMBASE, MEDLINE, PsycINFO, Scopus and Web of Science from inception up to May 2017. There were no date and language restrictions. We also searched for grey literature. Studies with statements mentioning roles, tasks and competencies pertaining to the role of peer reviewers in biomedical journals were eligible for inclusion. Two reviewers independently performed study screening and selection. Relevant statements were extracted, collated and classified into themes.

Results: After screening 2763 citations and 600 full-text papers, 209 articles and 13 grey literature sources were included. A total of 1426 statements related to roles were extracted, resulting in 76 unique statements. These were grouped into 13 emergent themes: proficient experts in their field (3 items), dutiful/altruistic towards scientific community (7 items), familiar with journal (2 items), unbiased and ethical professionals (18 items), self-critical professionals (4 items), reliable professionals (7 items), skilled critics (15 items), respectful communicators (6 items), gatekeepers ( 2 items), educators ( 2 items), advocates for author/editor/reader (3 items) and advisors to editors ( 2 items). Roles that do not fall within the remit of peer reviewers were also identified (5 items).

We also extracted 2026 statements related to peer reviewers' tasks, resulting in 73 unique statements. These were grouped under six themes: organisation and approach to reviewing (10 items), make general comments (10 items), assess and address content for each section of the manuscript (36 items), address ethical aspects (5 items), assess manuscript presentation ( 8 items) and provide recommendations ( 4 items).
\end{abstract}

Conclusions: Peer reviewers are expected to perform a large number of roles and tasks for biomedical journals. These warrant further discussion and clarification in order not to overburden these key actors.

Keywords: Biomedical, Roles, Tasks, Competencies, Journal, Peer reviewer, Scoping review

\footnotetext{
* Correspondence: kglonti@unist.hr

${ }^{1}$ Department of Psychology, University of Split, Faculty of Humanities and Social Sciences, Split, Croatia

${ }^{2}$ INSERM, U1153 Epidemiology and Biostatistics Sorbonne Paris Cité Research

Center (CRESS), Methods of Therapeutic Evaluation Of Chronic Diseases

Team (METHODS), F-75014 Paris, France

Full list of author information is available at the end of the article
}

(c) The Author(s). 2019 Open Access This article is distributed under the terms of the Creative Commons Attribution 4.0 International License (http://creativecommons.org/licenses/by/4.0/), which permits unrestricted use, distribution, and reproduction in any medium, provided you give appropriate credit to the original author(s) and the source, provide a link to the Creative Commons license, and indicate if changes were made. The Creative Commons Public Domain Dedication waiver (http://creativecommons.org/publicdomain/zero/1.0/) applies to the data made available in this article, unless otherwise stated. 


\section{Background}

Evidence indicates that there is a need to improve the quality of peer reviewer reports in biomedical journals $[1,2]$. Published biomedical papers may have a direct impact on clinical practice and inform policy. Therefore, it is crucial that peer reviewer reports, a screen before the diffusion of new knowledge, are of the highest quality possible to inform editors' decision on the fate of the manuscript $[3,4]$.

Unlike other professional groups, many editors and peer reviewers of biomedical journals operate largely without formal training. It is assumed that having expertise as an author provides, by default, the skills necessary to be a scientific editor and/or peer reviewer. However, this assumption is problematic, potentially having a number of negative implications for the overall quality of biomedical publishing [5].

Alongside the lack of standardised training, the lack of a clear, accepted definition of the roles and tasks of peer reviewers has also been highlighted [6]. A systematic review evaluated the impact of interventions aimed at improving the quality of peer review of randomised controlled trials (RCTs) for biomedical publications. The authors concluded that clarification of the roles and tasks of peer reviewers would be a step forward in quality improvement of peer reviewing [2]. In fact, a recent study showed that the most important tasks in peer review, as perceived by peer reviewers evaluating RCTs, were not congruent with the tasks most often requested by journal editors in their guidelines to reviewers [6].

Organisations such as the Council of Science Editors provide a general overview of reviewer roles and responsibilities [7]. However, within the biomedical field, the roles and tasks of peer reviewers are often closely related to the structural characteristics of the editorial process itself. For example, some (but not all) journals require peer reviewers to assess novelty and/or clinical relevance of articles in addition to assessing scientific rigour. Journal expectations of how a reviewer report should be written may vary. Some journals encourage reviewers to follow a specific structure in their reporting, whereas other journals prefer free text. Additionally, there may be differences between journals' requests for peer reviewer recommendations regarding whether an article should be accepted for publication or not. Furthermore, differences in roles and tasks between journals may also be linked to the organisational set-up and resources of the journals and publishers. Given these differences, we believe that it is important to distil the core roles and tasks to enable peer reviewers to meet basic, global standards. In order to do this, we first need to compile a comprehensive list of the different roles and tasks described in the literature.

While core competencies for biomedical journal editors have already been systematically identified [8] and agreed upon [9], we are unaware of any body of literature looking into peer reviewers' roles and tasks.

The aim of this scoping review is to determine the roles and tasks of peer reviewers as depicted in biomedical literature. For the purposes of this research, we consider 'roles' to refer to the overarching nature of peer reviewers' function, whereas 'tasks' refer more specifically to actions that fulfil these roles.

Our specific objectives were to answer the following two research questions while summarising the existing literature:

1. What are the expected roles of peer reviewers in the editorial peer review process in biomedical journals?

2. What are the range of tasks that peer reviewers are expected to perform for biomedical journals?

\section{Methods}

This scoping review was guided by the methodological framework proposed by Arksey and O'Malley [10], as well as the amendments made to this framework by Levac et al. [11] and by the Joanna Briggs Institute [12]. The framework consists of six consecutive stages: (1) identifying the research question, (2) identifying relevant studies; (3) study selection; (4) charting the data; (5) collating, summarising and reporting results; and (6) consultation. We performed the last stage through qualitative interviews, with results to be reported separately [13]. A study protocol containing all methodological details was published before conducting this scoping review [14]. Although initially specified in the protocol, we did not carry out the review of journal guidelines to peer reviewers. Due to the extensive volume of the initially proposed work, this aspect of the research will be carried out and published separately.

We used the PRISMA-ScR (Preferred Reporting Items for Systematic reviews and Meta-Analyses extension for Scoping Reviews) checklist to report our results (Additional file 6) [15].

\section{Study selection: inclusion and exclusion criteria}

Any article with a specific focus and/or statements mentioning roles, tasks and competencies pertaining to the contribution of peer reviewers to the journal editorial process was included. Articles referring solely to roles and tasks that were not related to manuscript peer reviewing in biomedical journals (e.g. grant peer review, professional performance review and peer review of teaching) were excluded. There were no date and language restrictions.

\section{Disciplines}

We adopted MEDLINE's journal selection criteria for our definition of health. This definition includes journals 
that are predominantly devoted to reporting original investigations in the biomedical and health sciences, including research in the basic sciences; clinical trials of therapeutic agents; effectiveness of diagnostic or therapeutic techniques; or studies relating to the behavioural, epidemiological, or educational aspects of medicine'. In order to ensure feasibility of the study, we did not include journals from the disciplines of psychology, education, physical or natural sciences.

\section{Study designs}

The review considered all study designs to be eligible. Based on findings from a preceding scoping review of competencies for scientific editors of biomedical journals [8], it was anticipated that a substantial proportion of relevant statements would be identified in publications that are not only presenting the results of research (subsequently termed 'research-based publications') but also in non-research-based publications including book chapters, commentaries and editorials, as well as grey literature. Therefore, we also searched for non-peer-reviewed resources on websites.

\section{Search strategy for peer-reviewed literature}

The Peer Review of Electronic Search Strategies (PRESS) 2015 Guideline statement was used to guide the electronic literature search strategies [16]. These were further refined in collaboration with a Health Sciences Librarian. Subsequently, the following databases were searched: Cochrane Library, Cumulative Index to Nursing and Allied Health Literature (CINAHL), Educational Resources Information Centre (ERIC), EMBASE (via Ovid), PsycINFO (via Ovid), MEDLINE (via Ovid), Scopus and Web of Science. There were no date or language restrictions. The search strategy for MEDLINE can be found in the online Additional file 1 . In addition, we hand-searched websites of JAMA, Nature and Science using keywords related to peer review to identify any additional literature that was not detected by the search strategy.

\section{Grey literature search}

We searched for grey literature on websites of existing networks (e.g. EQUATOR Network, New Frontiers of Peer Review (PEERE)), biomedical journal publishers (e.g. BMJ Publishing Group, Elsevier, Springer Nature, Taylor \& Francis, Wiley) and organisations that offer resources for reviewers (including educational courses, for example those provided by Cochrane and Publons) - Relevant blogs, newsletters (e.g. The METRICS Research Digest), surveys and reports of authors/reviewer workshops were also searched. We further hand-searched available abstracts from the various International Congresses on Peer Review and Scientific Publication $[17,18]$.

\section{Screening}

Following the execution of the search strategy, the identified records (titles and abstracts) were collated in a reference manager (Endnote) for de-duplication. The final unique set of records was imported into a systematic review paper manager (Covidence) that facilitated independent screening by two reviewers. The screening of titles and abstracts and subsequent full-text screening was performed independently by two reviewers (KG and DC). Disagreements between reviewers were resolved by consensus.

\section{Charting the data}

A data extraction form was developed a priori to capture information on each eligible document included in the review. General study characteristics extracted were as follows: first author name, year of publication, country of first author, language of publication and study design. For grey literature, we extracted the URL, title of the document, language of publication and who produced the document.

In addition, for all documents, we collected descriptions of any statements potentially relating to the roles and tasks of peer reviewers. Two people (KG, DC) carried out the data extraction. In the first step, data were extracted from eligible full texts into Microsoft Excel by KG. Subsequently, DC compared the full text of each eligible document with the extracted data on Microsoft Excel to ensure that all relevant information had been included.

\section{Collating, summarising and reporting the results}

Initially, all relevant statements (full sentences) related to roles from all data sources were extracted into a Microsoft Excel sheet by KG. Subsequently, each sentence was coded into smaller text units semantically as close as possible to the original, full sentence. Overlapping or duplicate text units were collated following discussion and agreement with DC, resulting in a list of unique statements for roles. Finally, we grouped these statements into emergent overarching themes to provide a better overview of results. All relevant statements (full sentences) related to tasks from all data sources were also extracted into a Microsoft Excel sheet by KG and mapped using pre-defined categories adapted from work carried out by Hirst and Altman [19]. In order to produce a meaningful list, we only included tasks that would apply to all types of studies. Tasks that are not common to all types of studies, for example, those related specifically to RCTs and systematic reviews, were not extracted (Additional files 7 and 8).

\section{Results}

\section{Literature search}

A total of 23,176 records were returned by the search strategy which included a substantial number of records 
related to 'hospital peer review'. In the first step, one researcher (KG) screened all irrelevant records out by title and abstract, leaving 2763 possibly relevant articles which were then screened by two reviewers by title and abstract (KG and DC). Six hundred records were eligible for full-text screening. Disagreements regarding eligibility were resolved through discussion and achieving consensus between the two reviewers. Subsequently, 391 biomedical publications were excluded, leaving 209 publications that met the inclusion criteria (Fig. 1) . From these 209 publications, there were 24 original research articles, 45 review articles and 140 book chapters, editorials, commentaries, letters and tutorials. We also included 13 grey literature sources.

\section{Research-based publications}

A total of 24 publications from the database search were considered relevant to the roles and tasks of peer reviewers in biomedical journals (Additional file 2).

Only one of these articles was primarily focused on roles and tasks. Seven studies reported on surveys, eight were descriptive studies and two were randomised controlled trials (RCT). The remaining five articles comprised a randomised trial, two intervention studies and two systematic reviews. Publication dates ranged from 1991 to 2016. Most of the studies were published in $2013(n=4)$ and $2005(n=3)$.

All articles were written in English. Eleven of the studies' first authors were based in the USA, three in the UK, two in France and one each in Australia, Canada, Hong Kong, India, Italy and Japan. The remaining two studies did not include details on the first authors' country affiliation.

\section{Non-research-based publications}

A total of 185 non-research-based publications were considered relevant.
Overall, 45 publications were review articles (Additional file 3). For the review articles, the date of publication ranged from 1974 to 2016; $2008(n=6), 2014$ $(n=5)$ and $2015(n=5)$ were the three years with the most studies. Two review articles were in Spanish and 41 in English. This sample included 23 studies with first authors originating from the USA, five from the UK, four from Australia and Spain and one from Canada, Greece, India, Japan, Korea and Palestine.

The remaining 140 publications consisted of 122 editorials, two book chapters, 12 commentaries, two letters and two tutorials (Additional file 4). The publication dates ranged from 1983 to 2017; $2016(n=15)$ and 2014 $(n=15)$ were the two years with the most studies. All articles were written in English except for two articles that were written in Portuguese. This sample included 48 studies with first authors based in the USA; 10 in the UK; nine in Canada; seven in Australia; four in Brazil; three in Germany; two in Denmark, India, Portugal and Spain; and one each in Austria, Croatia, The Netherlands and Singapore.

\section{Search of networks and publishers}

The search of networks and publishers resulted in 13 additional documents from websites. Among the sample, four documents were blogs/column, five were training/ webinar documents and two were guidelines from professional associations, societies and organisations. Lastly, two were guidance documents by publishers (Additional file 5).

\section{Collating and summarising the data}

In an effort to create a useful summary of the data, we collated and combined the statements retrieved from all included sources in Table 1 and Table 2, where we present a detailed breakdown of all themes and related

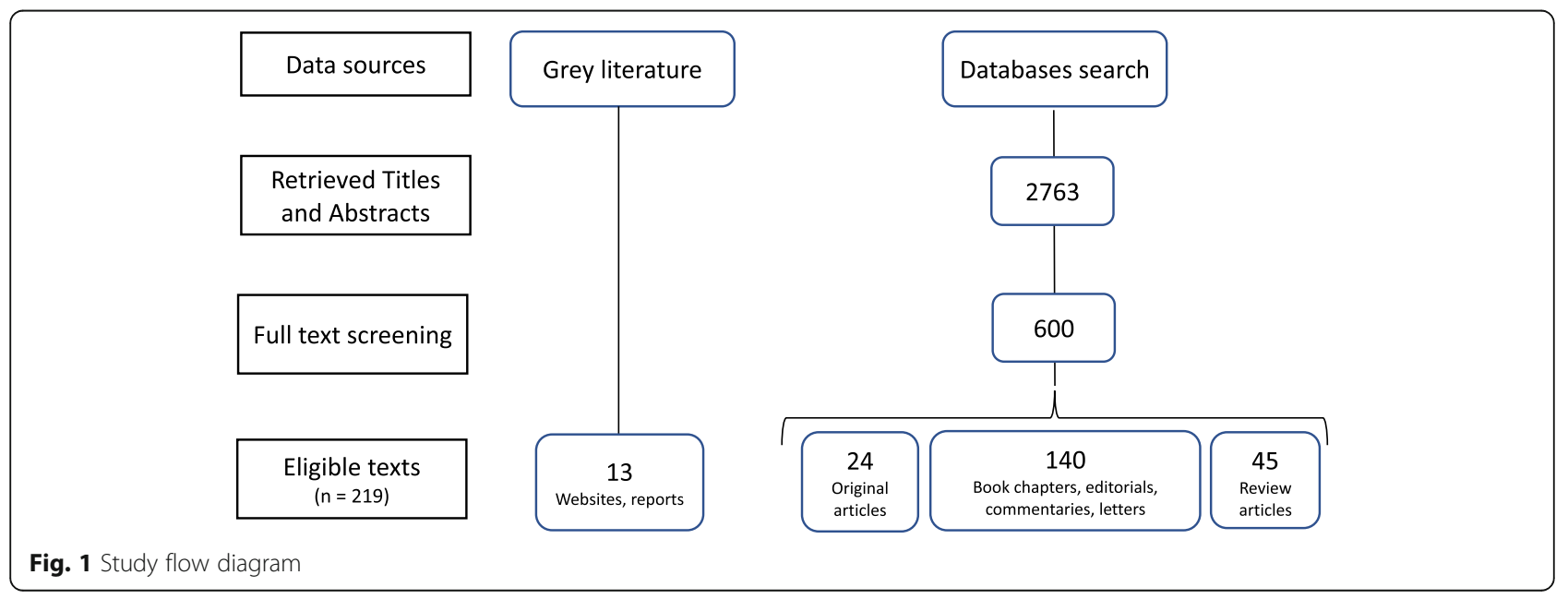


Table 1 Role-related statements ('roles' refer to the overarching nature of peer reviewers' function. The statements are ranked by numerical frequency. Each statement is linked back to the specific papers in the Additional files 2, 3, 4 and 5)

Peer reviewers should be..

Proficient experts in their field

Dutiful/altruistic towards the scientific community

Familiar with journal

Unbiased and ethical professionals
Be expert in the subject area/matter/field and/or be familiar with/trained in research methods and statistics

Be actively involved in research and have experience of conducting research and publishing scientific papers

Be familiar with reporting guidelines

Consider peer reviewing to be a responsibility, duty and obligation to the field and to the scientific community

Consider the act of peer reviewing as an honour and a privilege

Indicate willingness to re-review the manuscript

Be aware of one's role, responsibilities and rights as a peer reviewer

Perform reviewing task altruistically/gratis

End one's appointment as reviewer to create opportunity for others

Act regularly as peer reviewer

Be familiar with journal's mission, review process, review criteria, guidelines (i.e. both author and reviewer guidelines) and forms prior to starting the review

Guide the substance and direction of a journal

Declare/avoid potential or actual conflict of interest with others

Be fair: evaluate manuscript in a fair manner

Be objective: objectively judge all aspects of the manuscript

Be unbiased in their assessment: peer reviewers should have an unbiased attitude towards an author's gender, previous work, institution and nationality

Review ethically: they should not use the obtained information in any way

Be honest/frank

Maintain integrity of the peer review process and not communicate with authors during the review process

Inform editor if a colleague will help or has helped with review

Review ethically: they should not copy and plagiarise

Be aware of their own biases: peer reviewers should recognise their potential biases and hold them in check be destroyed

Review ethically: in general terms, peer reviewers are expected to undertake task in an ethical and diligent manner

Be familiar with fundamental issues of publication integrity

Decline review request if these cannot be performed in an unbiased manner

Review ethically: they should not ask for their own articles to be cited

Review ethically: they should not delay publications purposefully Pior to accepting review request, determine whether the manuscript is of expertise)

Be aware of own limitations: recognise and communicate them to the editors. If needed, recommend review by an expert (e.g. statistician)

Be innovative and open to new ideas

Peer reviewers should consider reviewing as a learning exercise and evaluate

‥

5

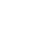

6

8

7

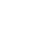

.

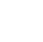

66


Table 1 Role-related statements ('roles' refer to the overarching nature of peer reviewers' function. The statements are ranked by numerical frequency. Each statement is linked back to the specific papers in the Additional files 2, 3, 4 and 5) (Continued)

Reliable professionals

Skilled critics

Gatekeepers

Educators

Advocates for author/editor/reader

Advisors to editors one's own performance as a reviewer, i.e. read other peer reviewers' reviews and thereby improve their own understanding of the topic and/or decision reached

Timeliness: meet journal deadline

Consider one's time availability prior to accepting review request 36

Be willing to devote sufficient time and attention to the review task 23

Respond to review requests in a timely manner 21

Inform the editor as soon as possible if proposed deadline to be exceeded 12

Immediately communicate to journal when cannot perform review 9

Suggest other reviewers if unable to review 7

Provide constructive criticism 87

Improve manuscript $\quad 84$

Be thorough/comprehensive/detailed/accurate 35

Be critical/sceptical: evaluate a manuscript in a critical manner 27

Be specific: provide authors with specific guidance on how to improve 26 their manuscript

Support comments with evidence: reviewers should document their comments and substantiate their points by referring to appropriate references and resources

Be clear: clearly explain concerns

Provide relevant comments: offer meaningful and reasonable comments 12 that can be addressed

Be consistent with comments to authors and editors: comments provided to the authors should be in line with confidential comments provided to editor in order to facilitate editors' decision-making, ensure consistency and avoid miscommunication.

Be systematic and methodological

Be balanced: provide a balanced critique 9

Be logical: provide logical arguments

Be concise/incisive $\quad 5$

Evaluate manuscripts in a consistent manner 4

Have intuitive capacity to detect faults and recognise quality 2

Be polite/courteous/respectful in the communication with authors 41

'Do unto others as you would have them do unto you': treat others as we 22 expect to be treated

Be positive: peer reviews should be written in a positive attitude and offer 13 praise for work well done

Be nice/kind/considerate 12

Be helpful: provide helpful comments 12

Be collegial: treat each manuscript as if it had been written by a 8 valued colleague

Maintain and improve manuscript quality and scientific rigour 15

Weed out unsuitable manuscripts that are not scientifically valid 11

Educate and mentor authors: provide a learning opportunity 15

Encourage authors: peer reviewers should encourage authors to 11 improve manuscript

Be an advocate for the editor $\quad 6$

Be an advocate for the author 6

Be an advocate to readers 2

Advise editors on the merits of manuscripts $\quad 40$ 
Table 1 Role-related statements ('roles' refer to the overarching nature of peer reviewers' function. The statements are ranked by numerical frequency. Each statement is linked back to the specific papers in the Additional files 2, 3, 4 and 5) (Continued)

\begin{tabular}{lll}
\hline 71 & $\begin{array}{l}\text { Provide confidential comments to editor } \\
\text { Peer reviewers should not... }\end{array}$ \\
72 & $\begin{array}{l}\text { Be decision makers: they should acknowledge that the final decision on the } \\
\text { publication of a manuscript rests with the editor }\end{array}$ & $\begin{array}{l}\text { Be copy editors (i.e. offer editorial comments about grammar and spelling) } \\
73\end{array}$ \\
75 & $\begin{array}{l}\text { Ask for unreasonable or pivotal change } \\
\text { Be overtly critical or too detailed: peer reviewers should not be generous } \\
\text { and should not ' } n \text { it-pick' or overwhelm the authors } \\
\text { Add additional requests in subsequent reviews that are not related to the } \\
\text { original revisions }\end{array}$
\end{tabular}

${ }^{a}$ Corresponds to the 'Role item(s)' columns in the tables related to roles in the additional files

${ }^{b}$ Number of extracted roles statements across all data sources in the scoping review

statements. Each statement is linked back to the specific papers in the Additional files 2, 3, 4 and 5.

A total of 1462 statements related to roles were extracted, resulting in 76 unique statements. These were grouped into 13 emergent themes where peer reviewers were considered to be proficient experts in their field (3 items), dutiful/altruistic towards scientific community (7 items), familiar with journal (2 items), unbiased and ethical professionals (18 items), self-critical professionals (4 items), reliable professionals (7 items), skilled critics (15 items), respectful communicators (6 items), gatekeepers (2 items), educators ( 2 items), advocates for author/editor/reader (3 items) and advisors to editors ( 2 items). Roles that do not fall within the remit of peer reviewers were also identified (5 items).

The 'skilled critics' and 'unbiased and ethical professionals' themes appeared most frequently. Figure 2 shows the identified themes according to the number of associated statements, with larger circles denoting a higher number.

We also extracted 2026 statements related to peer reviewers' tasks, resulting in 73 unique statements. These were grouped under six themes: organisation and approach to reviewing (10 items), make general comments (10 items), assess and address content for each section of the manuscript (36 items), address ethical aspects (5 items), assess manuscript presentation (8 items) and provide recommendations (4 items). The themes 'assess and address content for each section of the manuscript' had the highest number of statements while the theme related to ethical aspects had the lowest number (Fig. 3).

\section{Discussion}

This scoping review produced a comprehensive list of roles and tasks of peer reviewers, derived from a wide range of sources. We sought to complement an existing scoping review on competencies for scientific editors of biomedical journals [8]. While the focus of the scoping review is biomedicine, it is possible that many of the roles and tasks identified could apply more broadly to the discipline of science (e.g. Science, Technology, Engineering and Mathematics (STEM)).

From our analysis, we found incongruities between the position of the peer reviewer and the position of the editor as reported in the literature. For example, the link between peer reviewers' recommendations and editorial decision-making-where the former typically informs the latter-is often unclear. One of the roles identified in this article is for peer reviewers to keep in mind that they are not decision-makers regarding the ultimate fate of the manuscript. Such decision making is typically made by the editors who 'Synthesize reviews and make ultimate editorial decisions in light of peer reviewers' comments and other editors' comments' [9], to take this decision. At the same time, a key reviewer task emerging from this scoping review relates to the provision of a recommendation regarding the manuscript (decisionmaking: reject, accept, etc.). While peer reviewers should be expected to offer advice to editors on the merits of a manuscript, reviewer recommendations around whether or not to publish the manuscript might actually have a more substantial impact on final editorial decisionmaking than intended, thereby endangering any aspirations of editorial independence. Research indicates that peer reviewer recommendations have a direct influence on editorial decisions [20]. This becomes a problem when the quality of peer reviewer reports is questionable or when one of the many forms of bias that reviewers may display is present. Lee et al. describe bias as a 'function of author characteristics' which includes prestige bias, affiliation bias, nationality bias, language bias and gender bias. There might also be 'bias as a function of reviewer characteristics', such as when peer reviewers display content-based bias, confirmation bias, conservatism, bias against interdisciplinary research and publication bias [21].

Evidence from the field of meta-research-the study of science itself-indicates that the biomedical literature is replete with low-quality publications $[20,21]$ which have evidently successfully passed peer review. This in turn

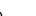

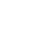

$-$ \\ -}


Table 2 Task-related statements ('tasks' refer to specific actions that fulfil 'roles' that refer to the overarching nature of peer reviewers' function. The statements are ranked by numerical frequency)

\begin{tabular}{|c|c|c|}
\hline Theme & Item $^{\mathrm{a}}$ & Tasks... \\
\hline \multirow[t]{10}{*}{ Organisation and approach to review } & 1 & Identify strengths and weaknesses \\
\hline & 2 & Identify flaws \\
\hline & 3 & Provide summary of key points \\
\hline & 4 & Differentiate between major and minor comments \\
\hline & 5 & Follows reviewer guidelines provided by the journal \\
\hline & 6 & Differentiate between fatal vs. addressable flaws \\
\hline & 7 & Address all aspects of the manuscript \\
\hline & 8 & Differentiate between general and specific comments \\
\hline & 9 & Identify missing information \\
\hline & 10 & Number each statement chronologically \\
\hline \multirow[t]{10}{*}{ Make general comments } & 11 & Determine validity/quality/technical merit/rigour \\
\hline & 12 & Assess originality \\
\hline & 13 & Assess novelty \\
\hline & 14 & Assess importance/significance \\
\hline & 15 & Comment upon relevance to practice/science (clinical relevance) \\
\hline & 16 & Comment upon contribution to the field \\
\hline & 17 & Highlight whether current literature is covered \\
\hline & 18 & Determine timeliness of the manuscript—is it topical? \\
\hline & 19 & $\begin{array}{l}\text { Determine whether reporting guidelines were followed } \\
\text { (i.e. appropriate selection and adherence by authors) }\end{array}$ \\
\hline & 20 & Comment upon conceptual/theoretical framework \\
\hline \multirow{25}{*}{$\begin{array}{l}\text { Assess and address content for } \\
\text { each section of the manuscript }\end{array}$} & Title & \\
\hline & 21 & Title is accurate \\
\hline & Abstract & \\
\hline & 22 & Accurate/conclusions consistent with results \\
\hline & 23 & Sufficiently detailed \\
\hline & 24 & Adequacy of abstract (in general) \\
\hline & 25 & Use of salient keywords \\
\hline & Introduction & \\
\hline & 26 & Clarity of study purpose and hypothesis \\
\hline & 27 & Adequacy of introduction (in general) \\
\hline & 28 & Appropriateness and adequacy of the literature review \\
\hline & 29 & Relevance of problem \\
\hline & Methods & \\
\hline & 30 & Adequacy of methods (in general) \\
\hline & 31 & Study design \\
\hline & 32 & Data analysis (methods and tests) \\
\hline & 33 & Use of statistics \\
\hline & 34 & Sampling strategy \\
\hline & 35 & Clarity and validity of statistical methods \\
\hline & 36 & How data was collected/reproducibility of methods \\
\hline & 37 & Methods appropriate for the research question \\
\hline & 38 & Risk of bias \\
\hline & 39 & Definition and measurement of variables \\
\hline & 40 & Inclusion/exclusion criteria \\
\hline & 41 & Follow-up \\
\hline
\end{tabular}


Table 2 Task-related statements ('tasks' refer to specific actions that fulfil 'roles' that refer to the overarching nature of peer reviewers' function. The statements are ranked by numerical frequency) (Continued)

\begin{tabular}{|c|c|c|c|}
\hline Theme & Item $^{a}$ & Tasks. & $\#^{b}$ \\
\hline & 42 & Assess different analysis parts separately & 11 \\
\hline & 43 & Reliable and appropriate tools used & 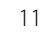 \\
\hline & 44 & Power analysis & \\
\hline & \multicolumn{2}{|c|}{ Results } & \\
\hline & 45 & Clarity of tables and figures & \\
\hline & 46 & Adequacy of results (general) & \\
\hline & 47 & Neutral and logical presentation of results & \\
\hline & 48 & No interpretation of results & 1 \\
\hline & 49 & Accuracy of raw data/appendices & 8 \\
\hline & \multicolumn{2}{|c|}{ Discussion/conclusion } & \\
\hline & 50 & Interpretation supported by data & 9 \\
\hline & 51 & Adequacy of discussion (general) & \\
\hline & 52 & Study limitations addressed & 2 \\
\hline & 53 & Research and policy implications (suggestions for future studies) & 1 \\
\hline & 54 & Summary reflects contents of the article & 13 \\
\hline & 55 & Generalizability of study conclusions & 5 \\
\hline & \multicolumn{2}{|c|}{ References } & \\
\hline & 56 & Appropriateness and accuracy of references & 5 \\
\hline \multirow[t]{5}{*}{ Address ethical aspects } & 57 & $\begin{array}{l}\text { Consider general ethical aspects and report on any specific } \\
\text { ethical concerns (including manipulation of data, plagiarism, } \\
\text { duplicate publication, inappropriate treatment of animal } \\
\text { or human subjects) }\end{array}$ & 5 \\
\hline & 58 & Report on ethical approval & 1 \\
\hline & 59 & Check specifically for plagiarism/fraud & 4 \\
\hline & 60 & Highlight competing interests of authors & 4 \\
\hline & 61 & No need to detect fraud & 2 \\
\hline \multirow[t]{8}{*}{ Assess manuscript presentation } & 62 & Overall readability & 4 \\
\hline & 63 & Presentation (general) & \\
\hline & 64 & Coherence/clarity and logical flow of the text & 3 \\
\hline & 65 & Grammar and spelling & \\
\hline & 66 & Organisation of the manuscript & 2 \\
\hline & 67 & Use of language & 2 \\
\hline & 68 & Length of the manuscript & 12 \\
\hline & 69 & $\begin{array}{l}\text { Check adherence to authors' guidelines (i.e. journal } \\
\text { guidelines for authors) }\end{array}$ & 9 \\
\hline \multirow[t]{4}{*}{ Provide recommendations } & 70 & $\begin{array}{l}\text { Recommendations on publication (e.g. no/minor/major } \\
\text { revisions, reject) }\end{array}$ & \\
\hline & 71 & $\begin{array}{l}\text { Comment on interest to journal readership/relevance for } \\
\text { journal scope }\end{array}$ & 5 \\
\hline & 72 & Complete (numerical) rating/checklist & 2 \\
\hline & 73 & Recommend another more suitable journal & 2 \\
\hline
\end{tabular}

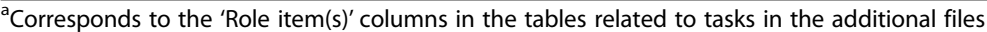

${ }^{\mathrm{b}}$ Number of extracted tasks statements across all data sources in the scoping review

suggests that the filtering function of journal editors is not being properly fulfilled. Thus, the question is whether the responsibility for publication of low-quality manuscripts is shared by both peer reviewers and editors or whether it should be borne solely by editors.
Another example of tension between these two stakeholders is the overlap that exists across certain tasks. For example, a key competency of journal editors should be to 'evaluate the scientific rigor and integrity of manuscripts' [9]. A study that analysed editorial discourse in a high- 
impact journal to provide insight into editorial decisionmaking found that factors related to science-such as research design and methods-were most often addressed during the internal discussion among the editors [22] . Concurrently, peer reviewers are expected to dedicate time to the evaluation and scoring of manuscripts' scientific rigour and integrity, in what seems to be a duplication of effort for potentially limited impact. Another perspective on this could be that the editor has made an evaluation and is asking the peer reviewers to do likewise, so it could be perceived as a validation of the editor's views concerning the scientific validity of the submission. It could also be seen as a way of using collective intelligence during the review process. However, peer reviewers are primarily consulted as experts in their field whose knowledge and expertise can at times be broader than the editors'. Thus, the pertinent question here revolves around their authority as experts and whether they are simply rubber-stamping the editors' decision.

Furthermore, the advocacy role of peer reviewers appeared several times in the included literature. According to some included articles, peer reviewers are variously expected to be advocates for authors, editors and/or readers. Whether this is a justifiable (and feasible) role is open to debate. Is it possible to be an advocate to all stakeholders simultaneously? If not, which stakeholders should take precedence and what would the order of priority be? The term 'advocates' needs to be unpacked and clarified in order for peer reviewers to understand what is expected from them in this particular area.

This overlap of roles, and the existence of apparently malleable boundaries between editors and peer reviewers, may have significant implications for the overall peer review process because there is the potential for misunderstandings to occur, as shown by Chauvin et al. [6]. Given the three problematic discrepancies described above, questions remain around their implications for reviewers' roles and tasks in terms of authority and responsibility.

The 13 themes identified in the list of reviewers' roles (Table 1) provided a clear construct of the ideal peer reviewer. Box 1 summarises these attributes, based on the most frequent statements identified in our review and the incongruities between the position of the peer reviewer and the position of the editor. Although this is a useful summary of the literature included, these roles need to be discussed critically beyond merely listing them for academic purposes. Instead, a more holistic approach, where these roles are critically discussed within the context of the broader scientific publication system in a way that acknowledges and recognises the complex and dynamic social relations that characterise the peer review process, should be adopted. Box 2 poses questions about the incongruities between the position of the peer reviewer and editor that need to be critically examined.

\section{Box 1 Construct of a peer reviewer}

Reviewers should be proficient experts in their field with training in research methods or statistics who-out of a sense of scientific responsibility and duty — provide unbiased, objective, thorough and specific yet constructive criticism to authors on how to improve their manuscript. Importantly, prior to commencing reviewing, self-critical reviewers should be confident about their availability and competence to review and be familiar with the journal's mission and review criteria and guidelines. Any potential or actual conflict of interest should be declared upfront or avoided entirely, in line with ethical norms. Reviewers should offer advice to editors on the merits of the manuscript while keeping in mind that they are not decision-makers regarding the fate of the manuscript. A polite, collegial attitude that promotes education of authors is vital. Lastly, they should maintain confidentiality throughout and deliver the report in a timely matter.

Complementary to the roles above, we identified 73 unique tasks that peer reviewers may variously be expected to perform. The large number of potential tasks identified is arguably excessive, especially since the majority of peer reviewers are not paid to perform these tasks and often receive little recognition for their work [23]. However, not all journals share all of these expectations. For example, a recent study on content of grading forms across a range of surgical journals found considerable variation in content, with relatively few journals requiring reviewers to address specific components of a manuscript. The study suggests that substantial variation exists in the grading criteria used to evaluate manuscripts submitted for peer review in this field, with a different emphasis placed on certain criteria correlated to journal impact factors. Grading forms of higher impact factor surgical journals more frequently addressed statistical analysis, ethical considerations and conflict of interest, whereas lower impact factor journals more commonly requested qualitative assessments of novelty or originality, scientific validity and scientific importance [24].

\begin{tabular}{l} 
Box 2 Critical questions related to roles and tasks of \\
peer reviewers \\
\hline - What is the link between peer reviewers' recommendations \\
and editorial decision-making? \\
- Who is responsible for publication of low-quality manuscripts? \\
- Is there overlap across certain roles and tasks (e.g. expert \\
evaluation, advisors)? \\
- What are the consequences of existing malleable boundaries \\
of authority and responsibility on the review process?
\end{tabular}




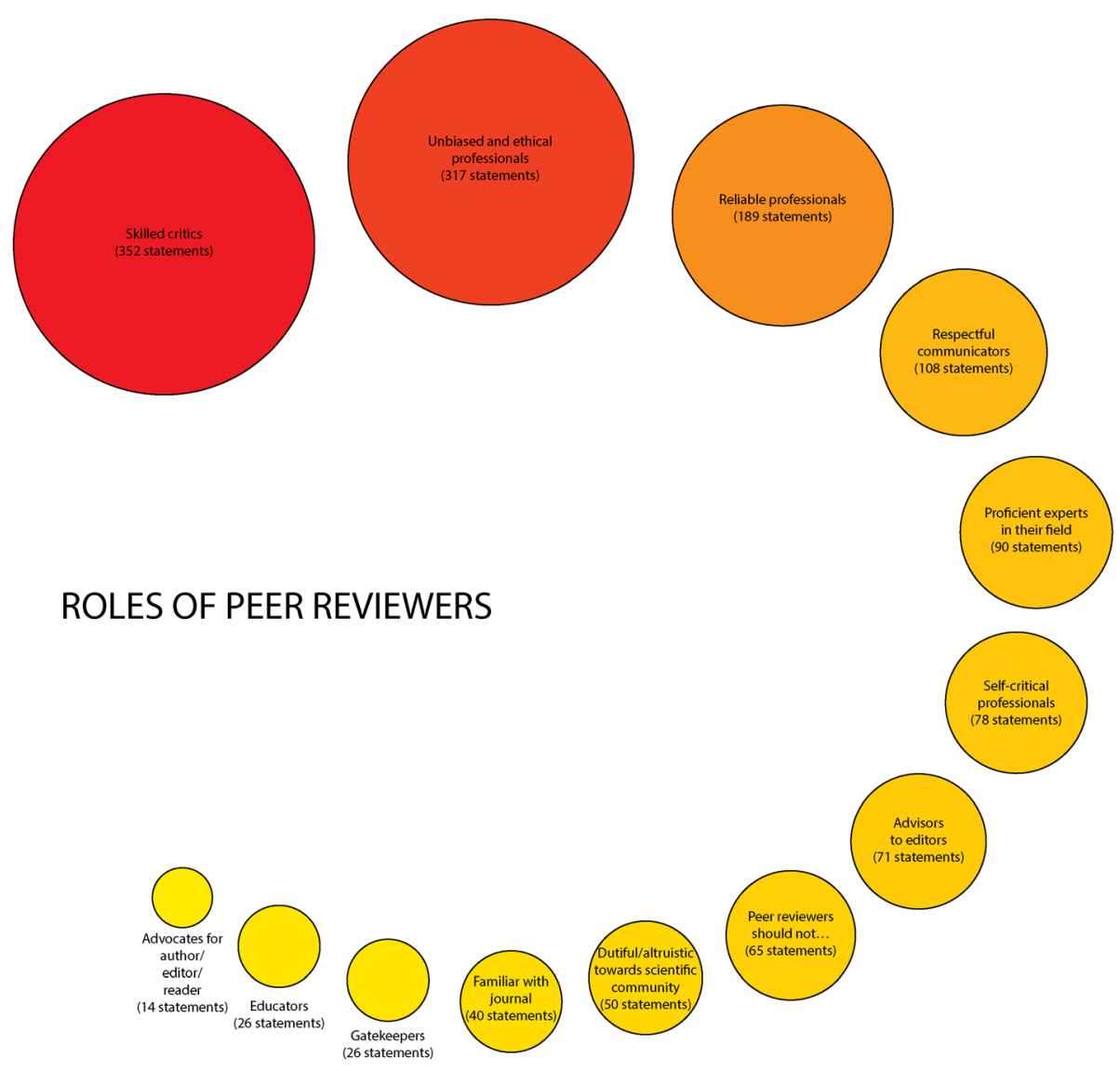

Fig. 2 Themes related to roles of peer reviewers

We also observed several contradictions. For example, there was some discrepancy as to whether detection of misconduct and fraud should fall within the remit of peer reviewers. However, in order to be able to detect fraud, it is likely that reviewers would need to check and verify the raw data of a study. Besides being impractical, this would almost certainly discourage prospective reviewers from participating in the already time-consuming peer review process. Research suggests that a small portion of the scientific community is already carrying out a disproportionate amount of peer reviewing [25], with the potential of contributing to downgraded peer review standards. Furthermore, journals often have more opportunities to check certain aspects related to misconduct, for example by using software to detect plagiarism. A study that identified 'highly rated' competency-related statements for biomedical editors found widespread agreement among editors that identifying and addressing allegations of fraud or plagiarism was a key competency [26] that should be performed by the editor, not by the peer reviewer.

There was also discrepancy regarding whether peer reviewers should engage in copy editing. Although the majority of included articles stated that copy editing does not fall within the duty of peer reviewers, several articles specifically mentioned that reviewers should offer grammatical and linguistic improvements. One could argue that this is the role of the copy editing team members at the journal, who are specifically trained to identify and address such aspects of the manuscript, whereas peer reviewers might not necessarily be sufficiently familiar with linguistic nuances to do so. The time potentially taken up by copy editing is also worth considering. A study found that lack of time is the principal factor for peer reviewers of biomedical journal in their decision to decline a peer review [27]. The time of peer reviewers is precious; therefore, their primary focus should be on the improvement of scientific content rather than the linguistic fine-tuning.

We found variation in the level of detail provided. Certain tasks were vaguely described. For example, statements such as 'check adequacy of abstract' or 'assess manuscript presentation' were not specific enough in terms of what exactly is required. Such generic statements are not helpful in explaining what editors expect, particularly to new or inexperienced peer reviewers. Vague guidance may result in vague peer review. One simple 


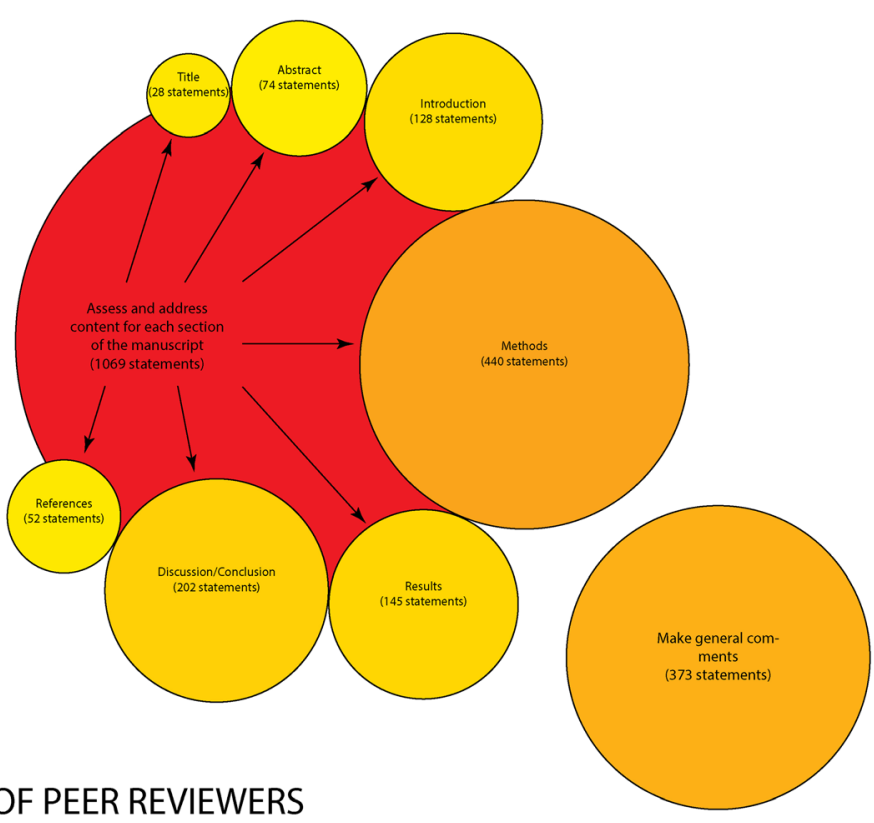

\section{TASKS OF PEER REVIEWERS}
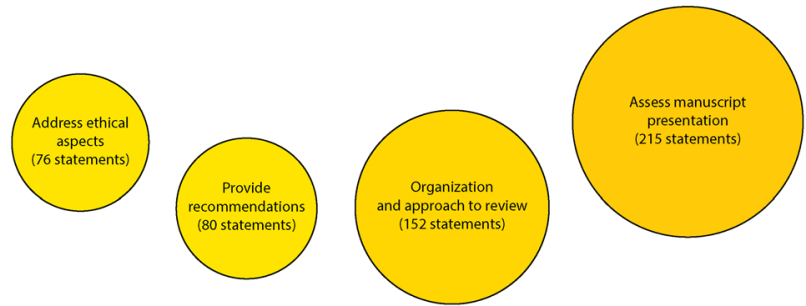

Fig. 3 Themes related to tasks of peer reviewers

but straightforward way of addressing this would be to thoroughly review and revise guidance provided to peer reviewers.

The term 'advocate' appeared several times in the included literature. According to some included articles, peer reviewers are variously expected to be advocates for authors, editors and/or readers. Whether this is a justifiable role is open to debate. Is it possible to be an advocate to all stakeholders? If not, which stakeholders should take precedence and what would the order of priority be? The term 'advocates' needs to be unpacked and clarified in order for peer reviewers to understand what is expected from them in this particular area.

Based on findings from a preceding scoping review of competencies for scientific editors of biomedical journals [8], it was anticipated that a substantial proportion of relevant statements would be identified in grey literature, rather than in peer-reviewed literature. Therefore, sources of grey literature were searched to supplement the database search strategy in the identification of task and rolerelated statements. Due to the sheer quantity of potentially relevant grey literature available on the web (e.g. websites of publishers), we have taken a pragmatic approach and focused on selected sources from official organisations that deal with peer review and which were also identified in the scoping review of editor competencies [8]. We also included some popular training courses for peer reviewers. However, we recognise that this is by no means comprehensive and we may have missed some potentially useful documents.

We were able to extract data from articles written in English, German, Spanish and Portuguese, but we are aware that the database and grey literature searches may not have included all available relevant literature due to language restrictions. Additionally, despite our best efforts, it is possible that we may have missed some aspects of peer reviewers' roles and tasks in our search. We preserved the wording used by authors to describe roles and tasks wherever possible and tried to ensure that any changes to wording reflected the spirit of what was being said when editing was necessary. However, it is possible that at times the subjective and selective nature of data extraction may have resulted in occasional misinterpretation of authors' intended statements. For example, some streamlining was necessary to ensure that the final list of roles and tasks was both manageable and useful; hence, it is possible that subtle differences between tasks or roles might have been smoothened out in an effort to remove 
redundant or overlapping items. We expect that some missing items will appear in the next stage of our research, where statements will be refined and expanded during a qualitative study with journal editors.

\section{Conclusion}

To our knowledge, this scoping review is the first attempt to systematically identify possible roles and tasks of peer reviewers in biomedical journals. This is the counter piece of the existing scoping review on competencies for scientific editors of biomedical journals [8].

As a standalone research piece, this study will primarily be helpful in demonstrating the extent and nature of existing literature on this topic, as well as displaying the type of roles and tasks requested (Additional files 7 and 8). As such, this will be relevant to a variety of audiences, including publishers, editors, peer reviewers and authors. For example, journal editors may be inspired to review their instructions to peer reviewers, whereas course developers might opt to update the content of training courses for peer reviewers.

In addition, a possible training initiative could include the use of 'open reports' (i.e. peer review reports and the authors' responses that are published alongside the relevant articles) which, according to a systematic review (2017) of the definitions of 'open peer review', is one of the seven main characteristics of open peer review [28]. These can be used as an educational tool for authors, editors and peer reviewers alike to unpick the different roles and tasks and to encourage a discussion on this subject. The reports can be prepared in such a way that they would reflect the emergent themes that we identified within our scoping review. Potential settings for such an educational intervention could be events such as faculty development meetings at Universities, where authors, editors and peer reviewers often mingle. The different themes could be presented using the concept of snippets [29] which are short, generally limited to $20-30 \mathrm{~min}$. The focus of a snippet is a single overriding communication objective (SOCO). Our identified themes are well suited to be transformed into snippets and can be taught in the allotted time using carefully curated open reports. This review will also inform a subsequent qualitative study with journal editors, with the aim of gaining further insight into their understanding of peer reviewers' roles and tasks [13] and eventually laying the groundwork for the development of a set of core competencies for peer reviewers of biomedical journals that could then be facilitated through a consensus exercise.

\section{Additional files}

Additional file 1: Search strategy. (DOCX $21 \mathrm{~kb}$ )

Additional file 2: Original articles. (DOCX $62 \mathrm{~kb}$ )

Additional file 3: Reviews. (DOCX $122 \mathrm{~kb}$ )
Additional file 4: Editorials. (DOCX $241 \mathrm{~kb}$ )

Additional file 5: Grey literature. (DOCX $32 \mathrm{~kb}$ )

Additional file 6: Prisma_ScR_Checklist. (DOCX $105 \mathrm{~kb}$ )

Additional file 7: Data_Roles. (XLSX $188 \mathrm{~kb})$

Additional file 8: Data_Tasks. (XLSX $178 \mathrm{~kb})$

\section{Abbreviations}

EQUATOR: Enhancing Quality and Transparency in Health Research; PRISMAScR: Preferred Reporting Items for Systematic reviews and Meta-Analyses extension for Scoping Reviews; RCT: Randomised controlled trial; SOCO: Single overriding communication objective; STEM: Science, Technology,

Engineering and Mathematics

\section{Acknowledgements}

We would like to express our thanks to Ms. Efstathia Gkioni (PhD candidate on the MiRoR project) for her help in reviewing this manuscript prior to submission.

\section{Authors' contributions}

All authors have made substantive intellectual contributions to the development of this manuscript. KG, DH, EC, IB and DM jointly contributed to the study conception and design. KG conceptualised the review approach and led the writing of the manuscript. DC contributed to the screening and analyses. DH led the supervision of the manuscript preparation. All authors provided detailed comments on earlier drafts and approved the final manuscript.

\section{Funding}

This project was supported by the European Union's Horizon 2020 research and innovation programme under the Marie Sklodowska-Curie grant agreement no. 676207.

\section{Availability of data and materials}

All data generated or analysed during this study are included in this published article.

Ethics approval and consent to participate

Not applicable.

\section{Consent for publication \\ Not applicable.}

\section{Competing interests}

The lead author (KG) has an advisory role with Publons Academy as well as DM. Two authors from this manuscript are members of the editorial board of BMC Medicine (DM and IB) under the 'Health Economics, Quality and Reporting' section. DM is also the co-Editor-in-Chief of Systematic Reviews and receives a small stipend for this function. The remaining three authors declare no competing interests.

\section{Author details}

${ }^{1}$ Department of Psychology, University of Split, Faculty of Humanities and Social Sciences, Split, Croatia. ${ }^{2}$ INSERM, U1153 Epidemiology and Biostatistics Sorbonne Paris Cité Research Center (CRESS), Methods of Therapeutic Evaluation Of Chronic Diseases Team (METHODS), F-75014 Paris, France. ${ }^{3}$ Paris Descartes University, Sorbonne Paris Cité, Paris, France. ${ }^{4}$ Department of Public Health, Faculty of Medicine and Surgery, University of Malta, Msida, Malta. ${ }^{5}$ Statistics and Operations Research Department, Barcelona-Tech, UPC, c/ Jordi Girona 1, C5-213, 08034 Barcelona, Spain. ${ }^{6}$ Center for Journalology, Clinical Epidemiology Program, Ottawa Hospital Research Institute, Ottawa, Canada.

Received: 4 February 2019 Accepted: 20 May 2019

Published online: 20 June 2019

\section{References}

1. Jefferson T, Rudin M, Folse SB, Davidoff F. Editorial peer review for improving the quality of reports of biomedical studies. Cochrane Database Syst Rev. 2006;(1). https://www.ncbinlm.nih.gov/pubmed/17443635. 
2. Bruce $R$, Chauvin A, Trinquart $L$, Ravaud $P$, Boutron I. Impact of interventions to improve the quality of peer review of biomedical journals: a systematic review and meta-analysis. BMC Med. 2016;14(1):85.

3. Kassirer JP, Campion EW. Peer review: crude and understudied, but indispensable. JAMA. 1994;272(2):96-7.

4. Moher D, Glasziou P, Chalmers I, Nasser M, Bossuyt PM, Korevaar DA, et al. Increasing value and reducing waste in biomedical research: who's listening? Lancet. 2016;387(10027):1573-86.

5. Moher D, Altman DG. Four proposals to help improve the medical research literature. PLoS Med. 2015;12(9):e1001864.

6. Chauvin A, Ravaud P, Baron G, Barnes C, Boutron I. The most important tasks for peer reviewers evaluating a randomized controlled trial are not congruent with the tasks most often requested by journal editors. BMC Med. 2015;13(1):1.

7. 2.3 Reviewer roles and responsibilities - Council of Science Editors [Internet] [cited 2018 Oct 23]. Available from: https://www.councilscienceeditors.org/ resource-library/editorial-policies/white-paper-on-publication-ethics/2-3reviewer-roles-and-responsibilities/

8. Galipeau J, Barbour V, Baskin P, Bell-Syer S, Cobey K, Cumpston M, et al. A scoping review of competencies for scientific editors of biomedical journals. BMC Med. 2016;14:16.

9. Moher D, Galipeau J, Alam S, Barbour V, Bartolomeos K, Baskin P, et al. Core competencies for scientific editors of biomedical journals: consensus statement. BMC Med. 2017;15(1):167.

10. Arksey H, O'Malley L. Scoping studies: towards a methodological framework. Int J Soc Res Methodol. 2005;8(1):19-32

11. Levac D, Colquhoun H, O'Brien KK. Scoping studies: advancing the methodology. Implement Sci IS. 2010;5:69.

12. Joanna Briggs Institute. The Joanna Briggs Institute reviewers' manual 2015. Methodol JBI Scoping Rev Joanna Briggs Inst JBI. 2015;

13. Glonti K, Hren D. Editors' perspectives on the peer-review process in biomedical journals: protocol for a qualitative study. BMJ Open. 2018; 8(10):e020568.

14. Glonti K, Cauchi D, Cobo E, Boutron I, Moher D, Hren D. A scoping review protocol on the roles and tasks of peer reviewers in the manuscript review process in biomedical journals. BMJ Open. 2017;7(10):e017468.

15. Tricco AC, Lillie E, Zarin W, O'Brien KK, Colquhoun H, Levac D, et al. PRISMA extension for scoping reviews (PRISMA-SCR): checklist and explanation. Ann Intern Med [Internet]. 2018 Sep 4 [cited 2018 Sep 25]; Available from: http:// annals.org/article.aspx?doi=10.7326/M18-0850

16. McGowan J, Sampson M, Salzwedel DM, Cogo E, Foerster V, Lefebvre C. PRESS peer review of electronic search strategies: 2015 guideline statement. J Clin Epidemiol. 2016;75:40-6.

17. Rennie $D$, Knoll E, Flangrin A. The international congress on peer review in biomedical publication. JAMA [Internet]. 1989;261. Available from: https:// doi.org/10.1001/jama.1989.03420050099049

18. Rennie D, Flanagin A, Godlee F, Bloom T. The eighth international congress on peer review and biomedical publication: a call for research. JAMA. 2015;313(20):2031-2.

19. Altman DG. Endorsement of the CONSORT statement by high impact medical journals: survey of instructions for authors. BMJ. 2005;330(7499):1056-7.

20. Vintzileos AM, Ananth CV, Odibo AO, Chauhan SP, Smulian JC, Oyelese Y. The relationship between a reviewer's recommendation and editorial decision of manuscripts submitted for publication in obstetrics. Am J Obstet Gynecol. 2014;211(6):703 e1-5.

21. Lee CJ, Sugimoto CR, Zhang G, Cronin B. Bias in peer review. J Am Soc Inf Sci Technol. 2013;64(1):2-17.

22. Dickersin K, Ssemanda E, Mansell C, Rennie D. What do the JAMA editors say when they discuss manuscripts that they are considering for publication? Developing a schema for classifying the content of editorial discussion. BMC Med Res Methodol. 2007;7:44.

23. Cintas P. Peer review: from recognition to improved practices. FEMS Microbiol Lett. 2016;363(12):fnw115. https://doi.org/10.1093/femsle/fnw115.

24. Davis $\mathrm{CH}$, Bass BL, Behrns KE, Lillemoe KD, Garden OJ, Roh MS, et al. Reviewing the review: a qualitative assessment of the peer review process in surgical journals. Res Integr Peer Rev. 2018;3(1):4.

25. Kovanis M, Porcher R, Ravaud P, Trinquart $L$. The global burden of journal peer review in the biomedical literature: strong imbalance in the collective enterprise. PLoS One. 2016;11(11):e0166387.

26. Galipeau J, Cobey KD, Barbour V, Baskin P, Bell-Syer S, Deeks J, et al. An international survey and modified Delphi process revealed editors' perceptions, training needs, and ratings of competency-related statements for the development of core competencies for scientific editors of biomedical journals. F1000Research [Internet]. 2017 Sep 4 [cited 2019 Jan 15];6. Available from: https://www.ncbi.nlm.nih.gov/pmc/articles/ PMC5605946/

27. Tite $\mathrm{L}$, Schroter $\mathrm{S}$. Why do peer reviewers decline to review? A survey. J Epidemiol Community Health. 2007;61(1):9-12.

28. Ross-Hellauer T. What is open peer review? A systematic review. F1000Research [Internet]. 2017 Aug 31 [cited 2019 Apr 9];6. Available from: https://www.ncbi.nlm.nih.gov/pmc/articles/PMC5437951/

29. Bar-on ME, Konopasek L. Snippets: an innovative method for efficient, effective faculty development. J Grad Med Educ. 2014;6(2):207-10.

\section{Publisher's Note}

Springer Nature remains neutral with regard to jurisdictional claims in published maps and institutional affiliations.
Ready to submit your research? Choose BMC and benefit from:

- fast, convenient online submission

- thorough peer review by experienced researchers in your field

- rapid publication on acceptance

- support for research data, including large and complex data types

- gold Open Access which fosters wider collaboration and increased citations

- maximum visibility for your research: over $100 \mathrm{M}$ website views per year

At BMC, research is always in progress.

Learn more biomedcentral.com/submissions 